\title{
O POSICIONAMENTO DO LOWSUMERISM NOS PROCESSOS DE CONSUMO: UM DISCURSO PERSUASIVO COMUNICACIONAL BASEADO EM PROPÓSITOS PUBLICITÁRIOS
}

\author{
The Positioning of Lowsumerism in the consumption processes: A persuasive \\ communication speech based on advertising purposes
El posicionamiento del Lowsumerism en los procedimentos de consumo: un discurso persuasivo comunicacional basado en propositos publicitarios

\section{Leticia Salem Herrmann Lima}

Docente do curso de Comunicação Institucional na Universidade Federal do Paraná leticia_herrmann@hotmail.com

\section{Resumo}

Este artigo visar promover discussões sobre o consumo e a publicidade com foco no lowsumerism, movimento que estimula o baixo (low) consumo (consumer). O termo em questão sugere reflexões sobre o que se produz e se consome, de forma a tornar o processo mais sustentável. O estudo resgata outros conceitos que, de alguma forma, se colocam com diferentes olhares as questões que envolvem movimentos estimuladores do baixo consumo, como o "minimalismo" e o "faça você mesmo" (DIY), pontuando características específicas de cada ideologia, a fim de refletir sobre possíveis impactos nos estudos do consumo e nas estratégias discursivas publicitárias. Evidencia-se, por meio de publicidades, estratégias apoiadas em propósitos lowsumeristas, minimalistas e DIY como forma de exemplificação do discurso persuasivo adotado pelas causas.

Palavras-chave: Processos de consumo. Lowsumerism. Propósitos publicitários.

\begin{abstract}
This article aims to promote discussions about consumption and advertising focusing on lowsumerism, a movement that stimulates low consumption. The term in question suggests reflections on what is produced and consumed, in order to make the process more sustainable. The study rescues other concepts that somehow pose with different looks the issues that involve stimulating movements of low consumption, such as "minimalism" and "do it yourself" (DIY), punctuating specific characteristics of each ideology, the to reflect on possible impacts on consumer studies and advertising discursive strategies. It evidenced, through advertising, strategies based on lowsumerist, minimalist and DIY purposes as a way of exemplifying the persuasive discourse adopted by the causes.
\end{abstract}

Key words: Consumption processes. Lowsumerism. Advertising purposes. 


\section{Resumen}

Este artículo pretende promover discusiones sobre el consumo y la publicidad con foco en el lowsumerismo, movimiento que estimula el bajo (low) consumo (consumer). El término en cuestión sugiere reflexiones sobre lo que se produce y se consume, para hacer el proceso más sostenible. El estudio rescata otros conceptos que, de alguna forma, se colocan con diferentes miradas las cuestiones que involucran movimientos estimuladores del bajo consumo, como el "minimalismo" y el "hágalo usted mismo" (DIY), puntuando características específicas de cada ideología, con el fin de reflexionar sobre posibles impactos en los estudios del consumo $\mathrm{y}$ en las estrategias discursivas publicitarias. Se evidencia, por medio de publicidades, estrategias apoyadas en propósitos lowsumeristas, minimalistas y DIY como forma de ejemplificación del discurso persuasivo adoptado por las causas.

Palabras clave: Procesos de consumo. Lowsumerism. Propositos publicitarios.

\section{INTRODUÇÃO}

Os estudos do consumo trazem à reflexão temas sociais e antropológicos que fomentam discussões variadas sobre a relação entre a produção, o consumo e os indivíduos. Dentre estes temas chama a atenção movimentos que, de alguma forma, se preocupam em tornar esta relação tríplice de forma sustentável. Considerando que a sociedade capitalista depende do consumo para engrenar seu sistema social, pensar em práticas sustentáveis pode ser uma saída positiva para questões que envolvem a produção desenfreada.

São inúmeras as razões que alteram as dinâmicas do consumo. Além da escolha particular dos indivíduos com relação as suas necessidades, pode-se pensar nas questões de estilo de vida, renda, espaço físico para armazenamento de objetos, aceitabilidade social pela posse de um bem, entre outros fatores. O consumo é algo complexo e suas práticas mostramse manifestadas das mais variadas formas. Por este motivo, despertou-se o interesse em observar um movimento contemporâneo que ganha corpo ao questionar as práticas de consumo, com relação a sustentabilidade no processo de compra, uso e descarte dos bens.

$\mathrm{O}$ atual estudo traz o lowsumerism como um movimento que estimula o consumo de forma equilibrada, pensando no uso do produto até sua última instância, na reutilização ou doação, em fazer a mercadoria circular de forma a usufruir dela o que for possível antes da realização de um novo ato de consumo. O lowsumerism, por sua vez, é o responsável por estimular o "reconsumo".

A proposta deste artigo é trazer conceitos e aplicações do lowsumerism como discurso publicitário e apresentar outros movimentos, que de alguma forma também discutem a relação do consumo e uso de produtos, mas com abordagens distintas a ideologia do lowsumerism, como o "minimalismo" e o "faça você mesmo" (DIY - do it yourself). 
Em um segundo momento, discute-se as estratégias de posicionamento de marcas com relação ao uso do propósito do lowsumerim no contexto publicitário e possíveis implicações em discursos comunicacionais voltados a sustentabilidade no consumo. Por último, serão apresentadas três campanhas publicitárias explicitando e diferenciando as estratégias do lowsumerism, do minimalismo e do faça você mesmo, evidenciando a existência de propósitos comunicacionais distintos no contexto das narrativas.

\section{AS PRÁTICAS DO CONSUMO E O DISCURSO PUBLICITÁRIO}

As práticas de consumo passam por transformações ao longo dos anos, estimuladas por temas que emergem de questões sociais e culturais. Preocupações com o meio ambiente, voltadas a sustentabilidade do planeta, são assuntos abordados no cotidiano do consumo. Várias indústrias remodelam seus negócios a partir do princípio da sustentabilidade. Por consumo entende-se o estabelecimento da aquisição de bens ocasionando o uso dos produtos, podendo ser firmado pela sua posse ou apenas por seu acesso, relação comumente estabelecida nas práticas digitais.

O consumo pode ser visto meramente como sendo de ordem material, mas se constitui pela relação simbólica estabelecida entre o bem e a mensagem consumida. É explicitado por Bourdieu (2007, p. 102) como sendo uma "economia das trocas simbólicas", que considera de um lado a mercadoria e de outro as significações que, em conjunto, definem as escolhas do processo em questão. Desta forma, atribui-se ao consumo um conjunto de significados que caracterizam os objetos pela presença de elementos que o identificam perante um grupo de pessoas, de acordo com padrões pré-estabelecidos por elas mesmas, ou pela própria cultura inserida naquele contexto social.

Don Slater (2002, p. 131) atribui as decisões de consumo a uma espécie de reprodução cultural, afirmando que "todo consumo é cultural", pois envolve significados que são partilhados com o outro e que as formas de consumo existentes são culturalmente específicas dentro de um modo de vida. As escolhas de consumo, por consequência, variam de acordo com a cultura de um povo, por levarem consigo um código específico com relação aos produtos e serviços adquiridos, que podem ser de importância apenas para culturas específicas e que para outras pode não transmitir o mesmo significado.

O processo de significação se apresenta de forma distinta. Por um lado, tem-se questões relacionadas aos mecanismos comunicacionais, que constroem situações 
estimuladoras do consumo e, de outro, as relações estabelecidas a partir das práticas sociais indutivas e inclusivas, explicadas por Baudrillard (2008) como sendo classificadas por:

1 - "Processo de significação e de comunicação", baseado num código em que as práticas de consumo vêm inserir-se e assumir o respectivo sentido. $\mathrm{O}$ consumo revela-se aqui como sistema de permuta e equivalente de uma linguagem, sendo abordado neste nível pela análise estrutural.

2 - "Processo de classificação e diferenciação social", em que os objetos/signos se ordenam, não só como diferenças significativas no interior de um código, mas como valores estatutários no seio de uma hierarquia. Nesta acepção, o consumo pode ser objeto de análise estratégica que determina o seu peso específico na distribuição dos valores estatutários (com a implicação de outros significantes sociais: saber, poder, cultura, etc.) (BAUDRILARD, 2008, p. 66).

As condutas do consumo são realizadas ancoradas nestes princípios, que orientam escolhas das mais diversas. Ressalta-se que a mídia, representada aqui pelos meios de comunicação, possui influência sobre o consumo na medida em que é apropriada pela publicidade com funções de propagação de mensagens comerciais. Tais elementos constituem um cenário propício a gerar influências no sentido macro, ao recorrer aos meios de comunicação de massa como canal fonte de emissão publicitária, ou de formas mais pontuais, utilizando influenciadores em mercados de nichos específicos.

O consumo, ao mesmo tempo, pode ser includente ou excludente. Includente quando se configura como parte de um conjunto de elementos que identificam grupos pelo uso comum de bens, ou excludente, quando os diferenciam a ponto de serem reconhecidos como de fora do grupo em questão, pelos objetos utilizados se distanciarem dos demais objetos utilizados pelo grupo. "A mercadoria deixou de ser simplesmente um bem de consumo, mas um símbolo que remete a um determinado estilo de vida e que inclui ou distingue socialmente os indivíduos" (VOLPI, 2007, p.92).

Por este motivo, não se isola neste texto padrões comunicacionais, culturais e sociais como influenciadores diretos das escolhas de consumo dos indivíduos. Tais fatores, em harmonia, direcionam os olhares publicitários na construção de mensagens com maior potencial persuasivo e consequentemente com maiores chances e características de se tornarem discursos mais eficazes.

É baseada nas questões que circundam a esfera do consumo, que a publicidade desenvolve técnicas para conquistar a atenção de indivíduos pré-dispostos a adquirir os bens comercializados. Por publicidade entende-se "um conjunto de técnicas de ação coletiva com o propósito de tornar conhecido um produto, serviço ou marca, promovendo assim uma atividade comercial" (GONÇALES, 2009, p. 07). 
Dentre as atribuições publicitárias, que envolvem a parte criativa, textual e de distribuição midiática, destaca-se aqui a atuação dos discursos publicitários como a materialização do percurso das campanhas comunicacionais. Estrategicamente a construção do discurso está presente em manifestações comunicacionais, mas evidencia-se seu papel com a concretização do poder persuasivo na publicidade com objetivos de consumo. “(...) A mensagem da publicidade se direciona para o mundo de sonhos no qual a realização do consumo não só é possível, mas também desejável” (CARRASCOZA, 2003, p. 32).

A ideia da linguagem publicitária é levar as mensagens criadas ao subconsciente do indivíduo com o intuito de promover decisões de compra a partir de mensagens persuasivas nesse sentido. Como afirma Gonçalves (2013, p. 83) o discurso publicitário tem como premissa o poder de "seduzir, provocar, intimidar ou mesmo incitar o consumo".

Um discurso publicitário convincente é constituído por uma associação semântica adequada com termos ligados entre si, estabelecendo conexões lógicas ao consumidor. “Assim, as palavras podem desenvolver vínculos no imaginário de quem as lê, como uma associação do subconsciente do público-alvo" (GONÇALVES, 2013, p.47).

A linguagem publicitária nas práticas de consumo, funciona como uma espécie de marcador simbólico, ficando responsável pelos estímulos à ação de compra. No entanto, ressalta-se a importância do estabelecimento de conexão correta com o tipo de discurso que será decodificado pelo receptor, para que a mensagem seja absorvida adequadamente por parte de cada público consumidor, pois a associação será realizada de forma a ser identificada por determinado grupo de pessoas com repertórios específicos.

Os discursos publicitários endossam as práticas de consumo reforçando as questões culturais e sociais articuladas em seus contextos. Reduz-se a eficácia publicitária ao separar o discurso midiático dos contextos culturais, por simplesmente a mensagem deixar de fazer sentido para aquele grupo de pessoas, que consomem bens de forma a torná-los visíveis ao seu grupo de convívio social.

\section{POSICIONAMENTOS NO CONSUMO: LOWSUMERISM, MINIMALISMO E O "FAÇA VOCÊ MESMO"}

Considerando os significados do consumo e os simbolismos que o constrói, se insere o lowsumerism como uma expressão simbólica de um tipo de consumo, voltado as práticas reflexivas e sustentáveis. O termo lowsumerism foi mencionado pela primeira vez em um 
artigo publicado no ano de 2015 pela empresa de tendências Box 1824, que mostrou o movimento como uma preocupação cotidiana nos estudos do consumo ${ }^{1}$.

A ideia do lowsumerism concentra-se nas questões do baixo (low) consumo (consumer), por defender uma causa baseada na necessidade de se ter um consumo cotidiano mais responsável. O termo será utilizado em inglês, pois sua tradução não representaria o conceito original, podendo dar alusão a uma diminuição do consumo, não sendo a base da interpretação correta sugerida nesse texto. Para a Box 1824 o movimento defende a ideia de se preservar um ciclo de produção, reutilização e descarte, similar ao conceito de frugalidade no consumo. Importante ressaltar que este termo é brasileiro e não encontrou-se nenhuma referência, até o presente momento, do uso da mesma terminologia em outros estudos da área.

Por este motivo, entende-se que o lowsumerism segue a linha do consumo cultural, por materializá-lo a partir de questões intrínsecas culturalmente como a conscientização da produção, por exemplo. A questão abordada não é vista apenas pelo seu cunho social, mas uma proposta de valor de consumo que precisa ser aceita culturalmente por um grupo de pessoas para que se perdure ao longo dos anos, por isso foi definida como um movimento pelos criadores do termo.

“Afinal, lowsumerism não significa parar de consumir, mas remodelar os desejos e reduzir o excesso. Abarcar estes valores de forma genuína é propor um convite à reflexão" (BARCELLLOS, 2016). O lowsumerism parte de um tipo de consumo baseado em uma forma de encarar a vida. Posiciona-se como um estilo político com relação as práticas de consumo, que vai do individual ao coletivo pelos reflexos causados pelo processo em si.

Estudos de consumo realizados nos Estados Unidos trazem a abordagem de um comportamento movido pela moderação na aquisição de bens, definido como "frugal lifestyles", associado ao termo "frugalidade" (PEPPER, JACKSON, UZZELLE, 2009, p.1). Frugal refere-se àquele indivíduo que é comedido, prudente no uso de recursos de consumo, de alimentos, de tempo ou dinheiro, fatores que vão ao encontro dos pilares utilizados nos conceitos recorrentes da sustentabilidade, definição que cabe na explicação do funcionamento do pensamento lowsumerista.

Já o consumo minimalista atua em outra instância, pois não está baseado em princípios engajados socialmente. O minimalismo volta-se as questões do "eu" como uma forma de desapego a materialidade. Na busca por teorias que discutem minimalismo,

\footnotetext{
${ }^{1}$ A empresa criou um vídeo explicativo sobre o movimento denominado "The rise of lowsumerism”. Disponível em: <www.youtube.com/watch?time_continue=3\&v=jk5gLBIhJtA>. Acesso em 20 de set de 2017.
} 
encontrou-se questões mais voltadas a um estilo de vida, uma ornamentação de ambientes que discute questão de caracterização e identidade visual. Ao contrário do lowsumerism que reflete sobre o impacto do consumo socialmente, o minimalismo busca uma realização pessoal com a diminuição do consumo, mas bastante contraditório se analisarmos pontualmente as questões que envolvem o processo.

Por mais que se encontre definições do minimalismo como estilo de vida, como é o caso do documentário "Minimalismo: um documentário sobre as coisas importantes", disponível na Netflix, os protagonistas minimalistas e escritores Joshua Fields Millburn e Ryan Nicodemus, fundadores do site "The Minimalists", deixam transparecer que a ideia defendida pelo movimento é de que compramos coisas que não precisamos. Nesse sentido, os autores ensinam os indivíduos sobre alternativas de consumo mais pontuais, práticas e em menor quantidade, propondo também um pensamento individualista nas escolhas de consumo. “O minimalismo é uma ferramenta para se livrar do excesso da vida a favor de se concentrar no que é importante - para que você possa encontrar a felicidade, a satisfação e a liberdade" (MILLBURN; NICODEMUS, 2017).

Boa parte das obras sobre minimalismo evocam o desapego ao excesso, com dicas de decoração, roupas e estilo de vida, o que mostra-se bastante distante do conceito de lowsumerism, que tem uma relação simbiótica com o processo em si e as implicações consigo e com o outro. O minimalismo apresenta também o luxo e o glamour num cenário de simplicidade. No documentário citado inclusive há uma incitação à compra de produtos de marca consideradas como de valor elevado, mas em pequenas quantidades, por atribuir aos produtos em questão uma categoria de superioridade com relação a qualidade. Tais elementos evidenciam que o minimalismo, de alguma forma, estimula um esforço diferenciado financeiro por parte do indivíduo, com relação ao capital necessário para consumir e construir o estereótipo minimalista.

Geralmente nas explanações sobre minimalismo a simplicidade não está associada a bens de consumo de baixo padrão, o que reforça a ideia de um movimento vertente de uma preocupação com a identidade visual limpa, podendo ser considerado então como um estilo de vida, sem preocupações explicitas diretas com fatores da sustentabilidade. Em um primeiro momento o minimalismo poderia ser visto como uma diminuição ao consumo, mas olhando as arestas do discurso é perceptível delinearmos estratégias do estímulo ao consumo por pouca quantidade, mas de forma luxuosa.

\footnotetext{
${ }^{2}$ No site os autores orientam sobre o minimalismo, divulgam suas obras e as agendas de palestras sobre o tema.
} 
Outro movimento, também presente nas vertentes dos estudos do consumo e que pode ter uma relação indireta com a sustentabilidade do processo é o "do it yourself - DIY”, ou "faça você mesmo", visto após a década de 50 estimulando projetos de reparos caseiros, se popularizando com o movimento punk, pelas alternativas independentes midiáticas em produzir música, que em uma de suas ideologias criticava o consumismo desenfreado. A ideia do movimento é comprar menos, reutilizando e confeccionando seus próprios produtos. A partir dos anos 2000, o movimento ganha nova dimensão resgatando a essência de seus primórdios utilizando o argumento da produção caseira de bens como um estilo de vida, baseada na sustentabilidade ambiental e na própria valorização da saúde e do bem de consumo.

Em entrevista concedida a revista Super Interessante, George McKay, professor de estudos culturais da Universidade de Salford, na Inglaterra, pesquisador e escritor sobre a cultura DIY, afirmou que embora a origem do movimento tenha surgido como uma reação ao consumismo, atualmente seu conceito se deturpou sendo utilizado como uma espécie de mensagem comercial por ser visto como um movimento "de status descolado". Ainda para McKay (2017) o movimento está se difundindo fortemente pelo mundo, porque

Isso tem a ver, em parte, com uma reação contra a cultura de massa, a mídia do espetáculo e das celebridades e a disseminação do consumo tecnológico mesmo que tenhamos de admitir que os defensores do DIY também usam esses mesmos meios para se comunicar e organizar sua cultura (MCKAY, 2017).

A afirmação do professor mostra a contradição entre o resgate da essência do "faça você mesmo", com a incorporação atual do movimento como uma espécie de modismo, principalmente propiciado por personalidades e programas de televisão que estimulam a culinária, a decoração e a confecção de roupas de forma caseira e artesanal. A ideia da comercialização e espetacularização do movimento é ressaltada quando observado a relação que esta prática possui nas mídias sociais. É possível averiguarmos tais questões em diversas instâncias e o Youtube tem sido um canal midiático potencial para isso, considerando a diversidade e infinidade de tutoriais dando dicas sobre como fazer as coisas sem precisar de um processo industrial.

Considerando tais fatos recorremos a ideia do consumo, que mostra-se presente neste processo, uma vez que para se criar os produtos, mesmo que caseiros, existe uma estimulação ao próprio consumo dos itens, mostrando-se desalinhado com questões puramente de sustentabilidade ao consumo. O "faça você mesmo" não caracteriza-se como um movimento 
ao baixo consumo, mas como uma possibilidade de cada indivíduo criar seus próprios bens, trazendo elementos da constituição do movimento como um estilo de vida, utilizado atualmente como um mecanismo estimulador do próprio consumo.

Para fechar o raciocínio, sugere-se o seguinte esquema sobre os conceitos dos movimentos (figura 1):

FIGURA 1: Conceitos gerais

\begin{tabular}{|l|l|l|}
\hline \multicolumn{1}{|c|}{ Lowsumerism } & \multicolumn{1}{|c|}{ Minimalismo } & \multicolumn{1}{|c|}{ Faça você mesmo } \\
\hline $\begin{array}{l}\text { Estimula um consumo } \\
\text { Consciente }\end{array}$ & Estimula o pouco consumo & $\begin{array}{l}\text { Estimula a criar os } \\
\text { próprios produtos }\end{array}$ \\
\hline Reutiliza & $\begin{array}{l}\text { Compra em pequenas } \\
\text { quantidades }\end{array}$ & Produz o que consome \\
\hline Doação e reciclagem & $\begin{array}{l}\text { Compra pela relação } \\
\text { qualidade x utilidade }\end{array}$ & $\begin{array}{l}\text { Cria, customiza, consome } \\
\text { e propaga }\end{array}$ \\
\hline Baseia-se em frugalidade & $\begin{array}{l}\text { Baseia-se na felicidade e } \\
\text { desprendimento material }\end{array}$ & $\begin{array}{l}\text { Baseia-se no caseiro e e } \\
\text { artesanal }\end{array}$ \\
\hline Preocupações com o outro & Preocupações para consigo & Preocupações para consigo \\
\hline Projeto político & Estilo de vida & Estilo de vida \\
\hline Cultura do cuidado & Cultura das escolhas & Cultura do artesanal \\
\hline
\end{tabular}

Considerando as abordagens conceituais trazidas neste tópico, resgata-se a diferença de posicionamento entre os três movimentos. A intenção deste estudo é, além de diferenciar os termos lowsumerism, minimalismo e "faça você mesmo", evidenciar a presença do lowsumerism nas estratégias publicitárias contemporâneas, providas de discursos integrativos para as marcas com foco em propósitos publicitários dos mais diversos.

O “propósito publicitário" (AUTOR, 2015) é representado pela causa central defendida pela marca, a fim de identificá-la como ideia principal das mensagens publicitárias, tornando-a superior que a própria marca. Um propósito pode ser visto como uma causa que defende a igualdade de gênero, inclusão social, direito das crianças, sustentabilidade ambiental, defesa dos animais, entre outros. O propósito publicitário apoia-se em questões relevantes para grupos específicos de consumidores e se apropria delas como parte da

${ }^{3} \mathrm{O}$ termo foi proposto em tese doutoral que estudou as campanhas publicitárias participantes do Festival Internacional da Criatividade Cannes Lions, durante 10 anos, evidenciando o foco do posicionamento das marcas em causas reconhecidas como de relevância social. 
natureza do posicionamento da marca de uma determinada empresa. Essa causa é utilizada como pilar na construção dos discursos publicitários contemporâneos integrativos.

As estratégias publicitárias são elaboradas a partir de discursos persuasivos criados com base em uma possível performance das marcas com relação ao argumento comunicacional. Cada tipo de consumidor faz uma leitura diferenciada dos anúncios publicitários e, por isso, o alicerce das campanhas é criar seus discursos ancorados em segmentos de consumidores. Uma marca pode se fortalecer em várias linhas comunicacionais simultaneamente, embora não seja a prática mais indicada por teóricos e especialistas da área (LUPETTI, 2001), pela possibilidade de confundir o consumidor na distinção de um produto, serviço ou marca. A seguir, serão apresentados exemplos publicitários que definem e distinguem o posicionamento de cada um dos movimentos de consumo: lowsumerism, minimalismo e faça você mesmo.

\section{CONFIGURAÇÕES DAS CAMPANHAS PUBLICITÁRIAS BASEAdAS EM ESTRATÉGIAS DE CONSUMO}

Conforme apresentado na tabela comparativa de palavras-chaves que caracterizam os movimentos (figura 1), o lowsumerism pertence a ordem da cultura do consumo pelo cuidado, exemplificada por meio da campanha da marca REI Patagonia (figura 2), com um discurso que incentiva a não consumir na época da Black Friday, data reconhecida pelo mercado por estimular o consumo prometendo desconto especial na ocasião. No anúncio encontra-se palavras de ordem que demostram a ideologia da cultura do cuidado com a sustentabilidade, representadas por: reduza, repare, reuse e recicle, encerrando o discurso do anúncio com "reimagine". $\mathrm{Na}$ assinatura do anúncio a marca traz o slogan: "Juntos nós reimaginamos um mundo onde a reutilização não pode ser negada". 
FIGURA 2: Anúncio da marca REI - Patagonia

\section{DON'T BUY THIS JACKET}

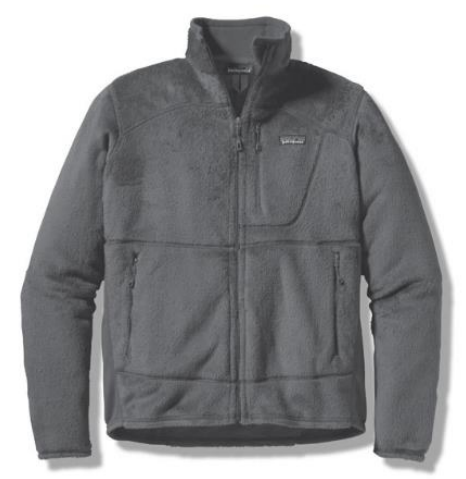

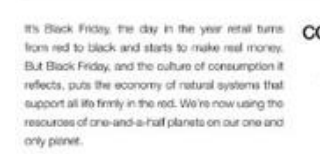
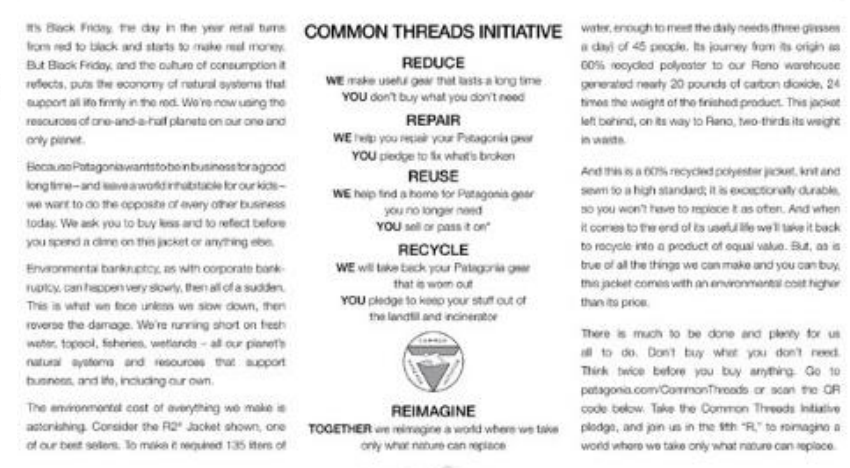

patagonia

Fonte: www.adweek.com/brand-marketing/ad-day-patagonia-136745/

Torna-se evidente que a estratégia publicitária adotada pela REI Patagonia conscientiza a população por meio de ações da marca. Certamente a campanha precisa das vendas para se manter, mas com a estratégia do "não consumo" trabalha o relacionamento e a empatia com os consumidores, numa proposta de princípios da frugalidade, se preocupando consigo, com o outro e no uso refinado do consumo, com melhores escolhas e proveito delas.

Como exemplos de publicidade minimalista, referenciam-se as campanhas das marcas Mc Donald's (figura 3) e Lego (figura 4). Percebe-se que em ambas as imagens publicitárias não apresenta traços de conscientização sobre o consumo, mas delineiam estilos de vida simplificados. O primeiro anúncio trata a satisfação do acesso ao wifi, tão presente na vida cotidiana, associado ao prazer da alimentação pela batata frita, produto carro chefe da rede de restaurantes, cujo anúncio é associado diretamente com as cores da marca. Já a campanha da Lego faz uma menção a criatividade simplificada, com a sombra de um navio utilizando duas peças do jogo Lego para compor o cenário de fundo azul, referenciado o mar. É perceptível que em ambos os anúncios as marcas assinam sutilmente no rodapé no canto inferior direito, pois a ideia do estilo simplificado é o que regulamenta a criação publicitária das peças. 


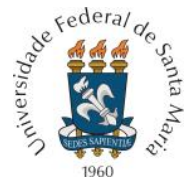

PROGRAMA DE PÓS-GRADUAÇÃO EM COMUNICAÇÃO DA UNIVERSIDADE FEDERAL DE SANTA MARIA

FIGURA 3: Anúncio da rede Mc Donald's

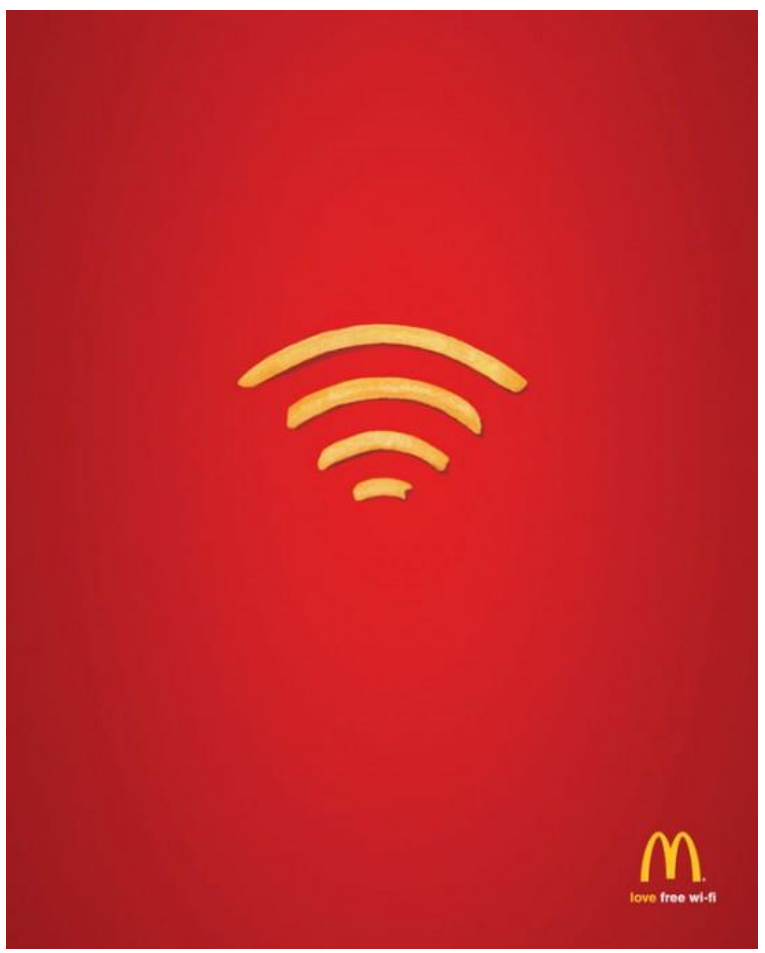

Fonte: www.criatives.com.br/2011/05/20-anuncios-minimalistas-brilhantes/

FIGURA 4: Anúncio da marca Lego

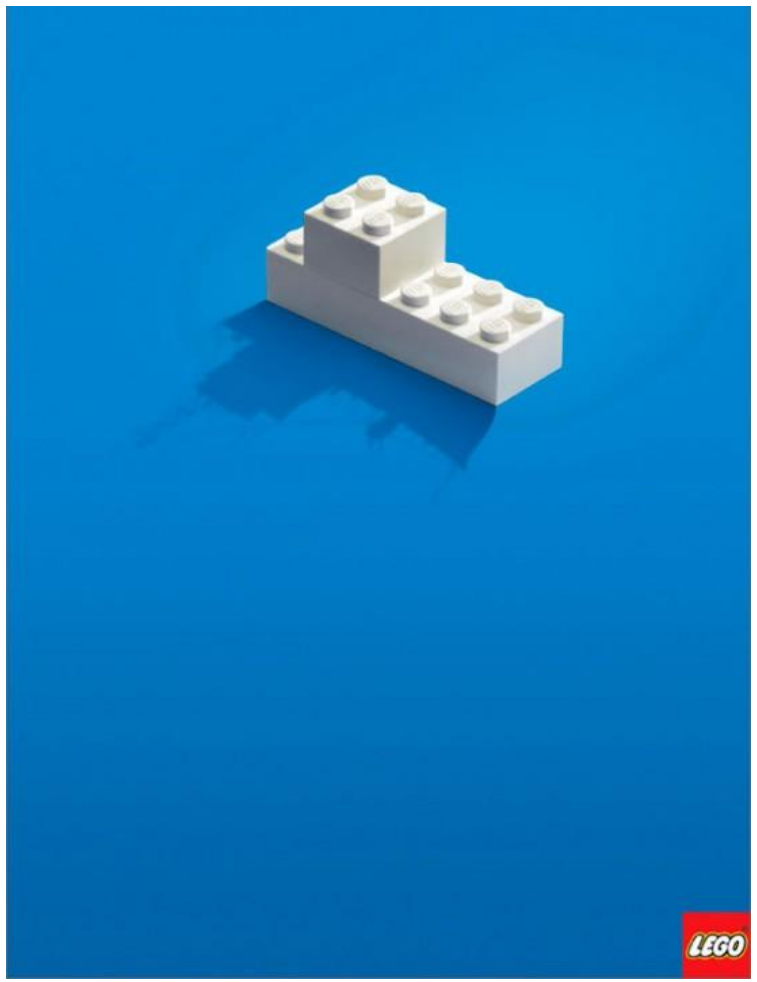


FONTE: www.criatives.com.br/2011/05/20-anuncios-minimalistas-brilhantes/

A cultura trabalhada nestas campanhas minimalistas está relacionada a ordem das escolhas, no sentido de promover um ambiente personalizado para o indivíduo, que é minimalista por questões de simplicidade e desapego, uma estética visual e um estilo de vida, não necessariamente relacionado a algum tipo de consciência ao se reduzir o consumo.

Como exemplo de campanha que se posiciona com características do movimento "do it yourself", o "faça você mesmo", temos a construção comunicacional do site da marca de roupas multinacional Levi's (figura 5), que traz entre seus conteúdos digitais uma página destinada a ensinar os consumidores a customizarem seus produtos Levi's. Neste conceito temos o reflexo da cultura do artesanal, estimulando o desenvolvimento de atividades manuais de forma a trabalhar os produtos considerando a personalização das peças. A ideia da campanha é produzir para si, de forma criativa e com alguma possibilidade de reutilização, mas não apresenta tal argumento de forma direta ao consumidor.

É presente nos processos do "faça você mesmo" a difusão da "arte" realizada, que funciona como uma espécie de cadeia produtiva artesanal mostrando-se como base da propagação do movimento de ver o outro fazer e replicar a criação com apropriações personalizadas. Mesmo que indiretamente a dinâmica do movimento reduza o consumo, sua proposta primária não tem esta preocupação como base, pois trabalha para o "feito à mão" como uma proposta de estilo de vida.

FIGURA 5: Anúncio da Levi's no site da marca

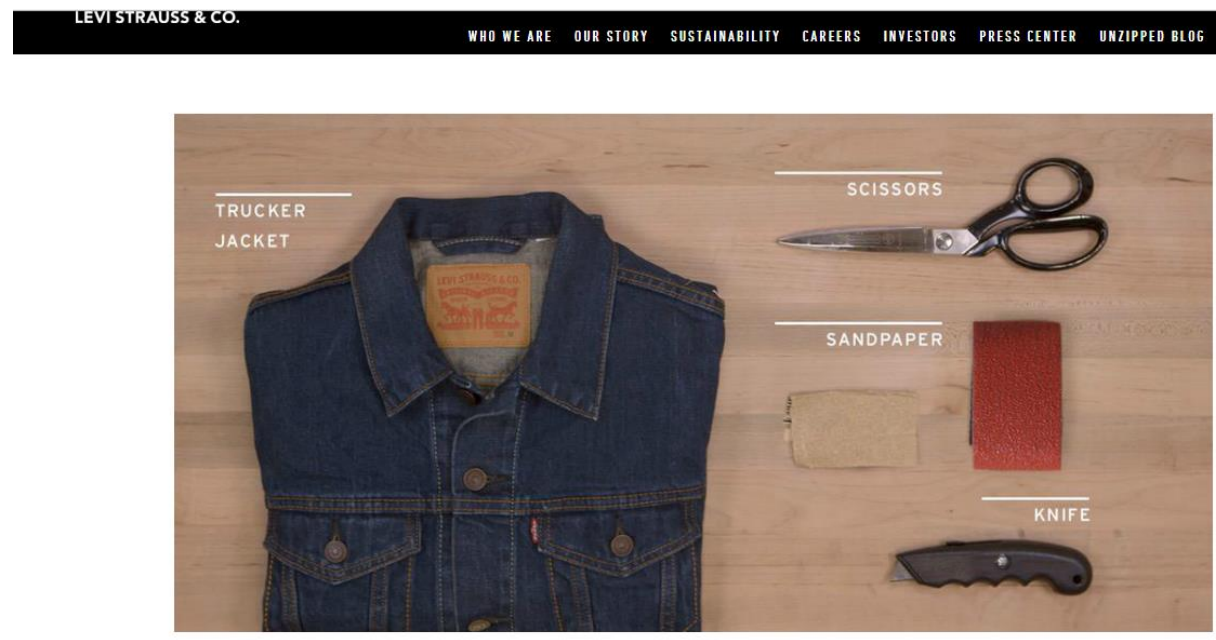

LEVI'S MASTER TAILORS TEACH YOU HOW TO CUSTOMIZE YOUR DENIM

Fonte: www.levistrauss.com/unzipped-blog/2015/06/levis-denim-diy-video-tutorials/ 
Construindo a estratégia publicitária da Levi's, tem-se a materialização do movimento com a possibilidade do próprio consumidor criar seus produtos personalizando de forma interacional, montando suas peças por tamanho, modelo, altura da barra, do cós, tipo de lavagem, entre outros. No site destinado ao e-commerce (figura 6), a marca oferece ao consumidor uma espécie de menu para customização dos produtos, seguindo a proposta que a mensagem publicitária traz no blog, também disponível na página web da marca.

FIGURA 6: E-commerce da Levi’s com a possibilidade de customização das peças

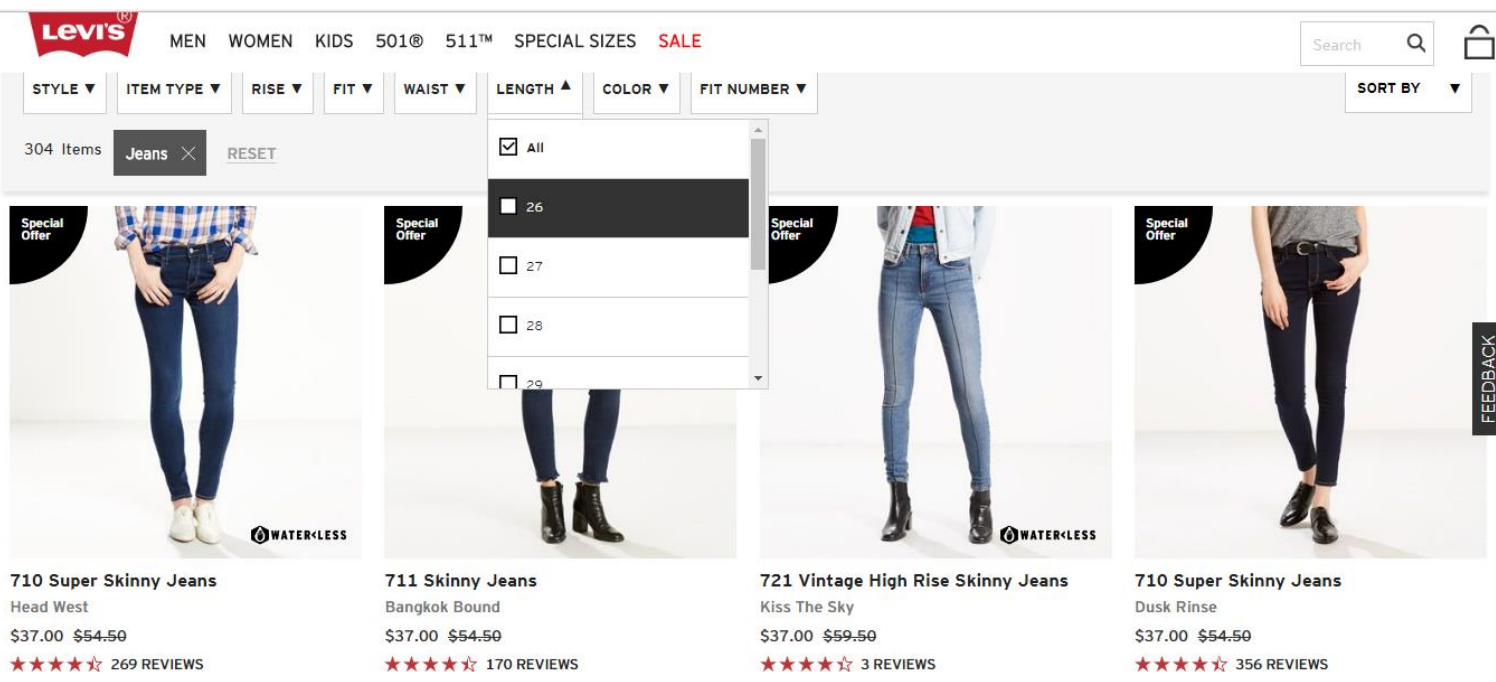

Fonte: www.levi.com/US/en_US/category/women/clothing/itemtype/jeans

Os exemplos publicitários evidenciam as diferenças conceituais trabalhadas neste texto, ao deixar claro os apelos textuais utilizados na criação dos discursos publicitários. Importante lembrar que um texto é composto também pela articulação das imagens que, no sentido das campanhas apresentadas, mostram-se como peças fundamentais na interpretação das mensagens.

O propósito publicitário de campanhas baseadas no lowsumerism é diretamente ligado aos fatores de sustentabilidade e seus modos de reprodução do consumo. O movimento é um compilado de preocupações individuais, coletivas e ambientais que equilibram as dinâmicas do consumo, de forma a se mostrarem representativas no cenário produtivo contemporâneo. 


\section{CONSIDERAÇÕES}

Os processos de consumo possuem variáveis que determinam as escolhas dos indivíduos de forma a orientá-los na aquisição de seus bens. Decorrente da inserção dos consumidores em meios sociais e culturais, as escolhas de consumo se moldam e se manifestam. O indivíduo, na busca de sua identidade, possui uma relação mútua com o outro e os produtos, serviços e marcas escolhidos por ele participam deste escopo constitutivo de elementos que o personalizam.

A publicidade, com seu papel persuasivo informacional, potencializa a característica dos bens de consumo a fim de estimular a aquisição de produtos e serviços dos mais variados, independente da necessidade de seu uso ou desejo por estimulação comunicacional. Dentre as narrativas discursivas comunicacionais, evidencia-se a presença de "propósitos publicitários" como causas defendidas pela marca a fim de entregar um posicionamento maquiado socialmente, baseado em um princípio ao bem comum como estratégia de inclusão da marca em um contexto grupal mais amplo. Neste caso, a marca assume para si a defesa da causa, deixando de lado o enaltecimento de seus produtos e serviços pela proposta de utilidade do bem, exaltando o valor social que endossa com sua comunicação.

Esses elementos com propósitos sociais caracterizam a construção de marcas contemporâneas, que passam a trabalhar valores humanos junto a publicização de seus negócios. Um propósito publicitário pode se apresentar de diversas formas, mas nesse estudo resgatou-se a ideia do movimento lowsumerism como foco de causa. A escolha foi fundada a partir de se trazer necessidades sustentáveis aos estudos do consumo, uma vez que é inevitável a indústria se pautar com o tema, pela própria necessidade ambiental recorrente de tal prática.

Como existem outros movimentos que se apoiam em olhares ao consumo de forma diferenciada e ampliada, optou-se por resgar, junto ao lowsumerism, o minimalismo e o faça você mesmo, por terem relação entre si, relatando no texto os diferentes posicionamentos de cada um deles. O lowsumerism é o único movimento entre os citados que se posiciona de forma política pensando no ciclo produtivo e no reflexo sobre o outro, sendo visto como o movimento da "cultura do cuidado". Já o minimalismo, apoia-se em estilo de vida posicionando-se como a "cultura das escolhas" de consumo e o "faça você mesmo", também fundado a partir do estilo de vida, mas centraliza-se na "cultura do artesanal". 
O lowsumerism, diferente dos demais movimentos citados, se apresenta como uma causa voltada ao consumo da ordem do frugal, visto como equilibrado e responsável. Importante lembrar que o movimento não prega a redução excessiva do consumo, mas sua utilização ordenada, pensando nas diversas esferas da sustentabilidade, que envolvem o social, o ambiental, o econômico, entre outros. O desafio de se trabalhar o lowsumerism nos enredos publicitários é justamente a contradição dos objetivos entre a produção e a sustentabilidade. De um lado, temos a publicidade que dita o estímulo ao consumo por meio de seus discursos e de outro o lowsumerism como um alerta ao equilíbrio entre a produção e o descarte.

Fica evidente, a partir dos exemplos trazidos neste artigo, que a publicidade encontra alternativas para apresentar seus discursos de forma a se enquadrar em propósitos lowsumeristas. É inevitável pensarmos em um discurso publicitário que se afaste por total das questões que estimulam o consumo pela natureza de sua função no contexto comunicacional. Contudo, ações criativas e bem planejadas conseguem encontrar uma linha equilibrada nessa relação de consumo que envolve a informação.

Importante lembrar que mesmo a publicidade sendo criativa, ao se trabalhar propósitos publicitários as causas precisam ser nobres e se retroalimentarem, no sentido de serem verdadeiras no âmbito de sua concepção processual e não apenas no escape comunicacional. Isso é potencializado ao se considerar um cenário volátil e participativo promovido pela comunicação nos sites de redes sociais, que deixará a marca vulnerável a interferência dos consumidores em caso de uma promessa de uma causa mentirosa.

O propósito do lowsumerism traz consigo tal desafio, de ser verdadeiro e gerar engajamento com a marca, não sendo apenas trabalhado como uma estratégia comunicacional da empresa, pois os valores trazidos no movimento são ampliados gerando reconhecimento social junto aos consumidores.

\section{REFERÊNCIAS}

BAUDRILLARD, Jean. A sociedade de consumo. Lisboa: Edições 70 Editora, 2008.

BIZ, Eduardo. Ponto Eletrônico. A principal tendência da atualidade: entenda a urgência do lowsumerism (2015). Disponível em: <http://pontoeletronico.me/2015/lowsumerismentenda/>. Acesso em: 20 de out. de 2017. 
BARCELLLOS, Renata. Ponto Eletrônico. Publicidade lowsumer: cultura de cuidado disseminada pela propaganda (2016). Disponível em:

<http://pontoeletronico.me/2016/publicidade-lowsumer/>. Acesso em: 20 out. de 2017.

BOURDIEU, Pierre. A economia das trocas simbólicas. 6 edição. São Paulo: Perspectiva, 2007.

BOX 1824. The Rise of Lowsumerism (2015). Disponível em:

<www.youtube.com/watch?v=jk5gLBIhJtA\&t=14s>. Acesso em: 20 de jan. de 2017.

CARRASCOZA, João Anzanello. Redação Publicitária: Estudos Sobre a Retórica do Consumo. 2. ed. São Paulo: Editora Futura, 2003.

CRIATIVES. 20 anúncios minimalistas brilhantes. Disponível em: <www.criatives.com.br/2011/05/20-anuncios-minimalistas-brilhantes/>. Acesso em: 20 de out. de 2017.

GONÇALES, Márcio Carbaca. Publicidade e Propaganda. Curitiba: IESDE Brasil, 2009.

GONÇALVES, Lilian S. Neuromarketing aplicado à redação publicitária. São Paulo: Novatec Editora, 2013.

AUTOR. Título da obra retirado seguindo as diretrizes para autores. Tese. Curitiba: UTP, 2015.

LEVIS. Site Levis. Disponível em: <www.levistrauss.com/unzipped-blog/2015/06/levisdenim-diy-video-tutorials/>. Acesso em: 20 de out. de 2017.

LUPETTI, Marcélia. Planejamento de Comunicação. São Paulo: Futura, 2001.

MCKAY, George. Revista Super Interessante. A volta da cultura do "faça você mesmo". Disponível em: <https://super.abril.com.br/cultura/a-volta-da-cultura-do-faca-voce-mesmo/>. Acesso em: 20 de out. de 2017.

MILLBURN, Joshua Fields; NOIODEMUS, Ryan. The Minimalists. Disponível em: <www.theminimalists.com>. Acesso em: 03 de out. de 2017.

NUDD, Tim. Adweek. Ad of the day: Patagônia. Disponível em: <www.adweek.com/brandmarketing/ad-day-patagonia-136745/>. Acesso em: 20 de out. de 2017.

PEPPER, Miriam; JACKSON, Tim; UZZELL, David. An examination of the values that motivate socially conscious and frugal consumer behaviours. International Journal of Consumer Studies 33 p. 126-136, 2009. ISSN 1470-6423. Disponível em: <http://onlinelibrary. wiley.com/doi/10.1111/j.1470-6431.2009.00753.x/full>. Acesso em: 10 de jan. de 2017.

SLATER, Don. Cultura do Consumo e Modernidade. São Paulo: Nobel, 2002. 
VOLPI, Alexandre. A história do consumo no Brasil. Do mercantilismo à era do foco no cliente. Rio de Janeiro: Editora Campus, Elsevier, 2007.

Publicitária e Relações Públicas com especializações em Marketing, Varejo e Gestão de Marcas. Mestre, Doutora e Pós-Doutora em Comunicação e Linguagens. Docente e vice-coordenadora no Curso de Comunicação Institucional na UFPR. Professora convidada em cursos de pós-graduação na UFPR, PUCPR, UTP e ESIC. Integrante dos grupos de pesquisa PRACCOM e COMXXI da UFPR. Pesquisadora, especialista e consultora nas áreas de consumo, mídia integrada, planejamento e neuromarketing.

\section{(2) $\odot \Theta(0)$}

Esta obra está licenciado com uma Licença Creative Commons Atribuição-NãoComercial-CompartilhaIgual 4.0 Internacional 